\title{
Bite Injury
}

National Cancer Institute

\section{Source}

National Cancer Institute. Bite Injury. NCI Thesaurus. Code C121559.

A wound inflicted by the teeth or fangs of an individual or animal. 